A foreign place called non-place. A reflection on the need of place and non-place architecture

\section{| RESUMEN |}

Se propone como acción crítica adentrarse en el concepto de No-Lugar, partiendo del término «extranjero» extraído de diferentes autores, para abrir un diálogo sobre los no-lugares, los lugares y su relación con la arquitectura, afín de reivindicar la necesidad del no-lugar para acceder al lugar.

\section{| ABSTRACT |}

With the objective of critical action a proposal is made that debates the concept of No-place starting from based on the term «foreigner» extracted from different authors, opening a debate on the non-places and places and their relationship to architecture, in order to assert the need for a non-place to access the place.

\title{
Un lugar extranjero llamado no-lugar Una reflexión sobre la necesidad del lugar y el no-lugar arquitectónico**
}

\section{EXTRANJERO}

«Decía que en realidad yo no tenía alma en absoluto y que no me era accesible ni lo humano, ni uno solo de los principios morales que custodian el corazón de los hombres. «Sin duda-agregó-, no podríamos reprochárselo. No podemos quejarnos de que le falte aquello que no es capaz de adquirir. (...) Sobre todo cuando el vacío de un corazón, tal como se descubre en este hombre, se transforma en un abismo en el que la sociedad puede sucumbir». Albert Camus, El Extranjero (1999).

Los no-lugares son percibidos como extranjeros, como exterior sin interior. Extranjeros como M. Meursault -protagonista de la obra de Camusausente: tanto de sí mismo como de lo que lo rodea, estando fuera de lugar, desprovisto de sentimientos que lo unan o conecten con el mundo.

Es un extranjero, un «extraño» (otro significado del vocablo francés étranger), en primer lugar para con él mismo y luego con todo(s) lo(s) demás. Un modesto trabajador argelino -como también lo fue el autor años antes- que vive una vida tranquila hasta que muere su madre. Con M. Meursault se comienza a percibir el olor a vacío, ese olor profundo que al entrar en un espacio terriblemente desolado nos impregna con su nada.

Este personaje cobija una insoportable ausencia, insoportable para los lectores, pues el protagonista no siente nada ya que está inmerso en el más profundo de los vacíos: el del alma.

Lo mismo sucede con Kafka, quien llegó a esa «cotidianeidad de lo grotesco» (Anders, 2007), hasta ese punto extraño y alienante, porque como Camus era un extranjero. También se aprecia en su obra la excentricidad, donde la figura principal se convierte en un héroe «en sentido negativo», héroe sin mundos al igual que Don Quijote, ya que es lo diametralmente opuesto a lo establecido, teniendo el ejemplo más fuerte con su personaje Gregor Samsa en LA MetAMORFosis.

Laura Gallardo Frías es arquitecta por la Universidad Politécnica de Cataluña. Doctora en Arquitectura y Urbanismo por la Universidad Politécnica de Madrid, con una tesis doctoral acerca del Lugar y el No-Lugar arquitectónico. Ha participado en estudios de arquitectura y en docencia e investigación en Barcelona, Toulouse y Santiago. Actualmente es Académica de la Universidad de Chile, donde se desempeña como profesora responsable del curso de Taller de Diseño Arquitectónico de segundo año y desarrolla diferentes investigaciones.

** Este artículo ha sido realizado en el proyecto de investigación FAU titulado: «Del no-lugar al lugar en la didáctica de proyecto arquitectónico», auspiciado por la Universidad de Chile, Facultad de Arquitectura y Urbanismo. 
1. Portada del libro de Abert Camus, L'ETRANGer (EL Extranjero), publicado en 1942 (Fuente: http://www.avizora.com/publicaciones/biografias/textos/albert_camus_0026.htm).

2. Cartel película Lo straniero (EL EXTrANJero), dirigida por Luchino Visconti, Italia, 1967 (Fuente: http://www.cln3.org/v/viscontiO1//lmages/117.html).

3. Cartel película THe MAN WHO WASN'T THERE, dirigida por los hermanos Coen, Québec, 2001 (Fuente: http://www.impawards.com/2001/man_who_wasnt_there_ver3.html).

4. Primera ilustración de la portada del libro Die VerWANDLUng (LA METAMORFosis), publicada en 1915, realizada por Ottomar Starke (Editorial Kurt Wolff Verlag, Leipzig) (Fuente: http://de.academic.ru/dic.nsf/dewiki/331277http://de.academic.rv/pictures/dewiki/75/Kafka_Starke_Verwandlung_1915.jpg).

5. SIN Título de George Grosz (1920) (Fuente: http://www.epdlp.com/cuadro. php?id=437).



«Estar ahí» significa para Kafka «estar eternamente llegando sin jamás acabar de llegar», o sea, no estar ahí; sin embargo, por otra parte, «como no puede negar que está de alguna manera en el mundo, tiene que revestir positivamente el no estar ahí, o sea, encontrar formas intermedias entre el ser y el no-ser». (Anders, 2007).

Kafka opera con lo espantoso, que es lo que nos mantiene a distancia (condición de todo lo artísticamente bello) y con lo bello (que es solo el inicio de lo espantoso, dice Rilke), ambos inaccesibles.

Esta mirada desde el exterior que infunde la característica de extranjero también se da con fuerte impacto en la obra de Grosz, quien con sus pinturas más que invitar al espectador lo aterroriza y de repente el sujeto se encuentra en el lugar del objeto y viceversa, es decir, el que mira y el que es mirado se intercambian.
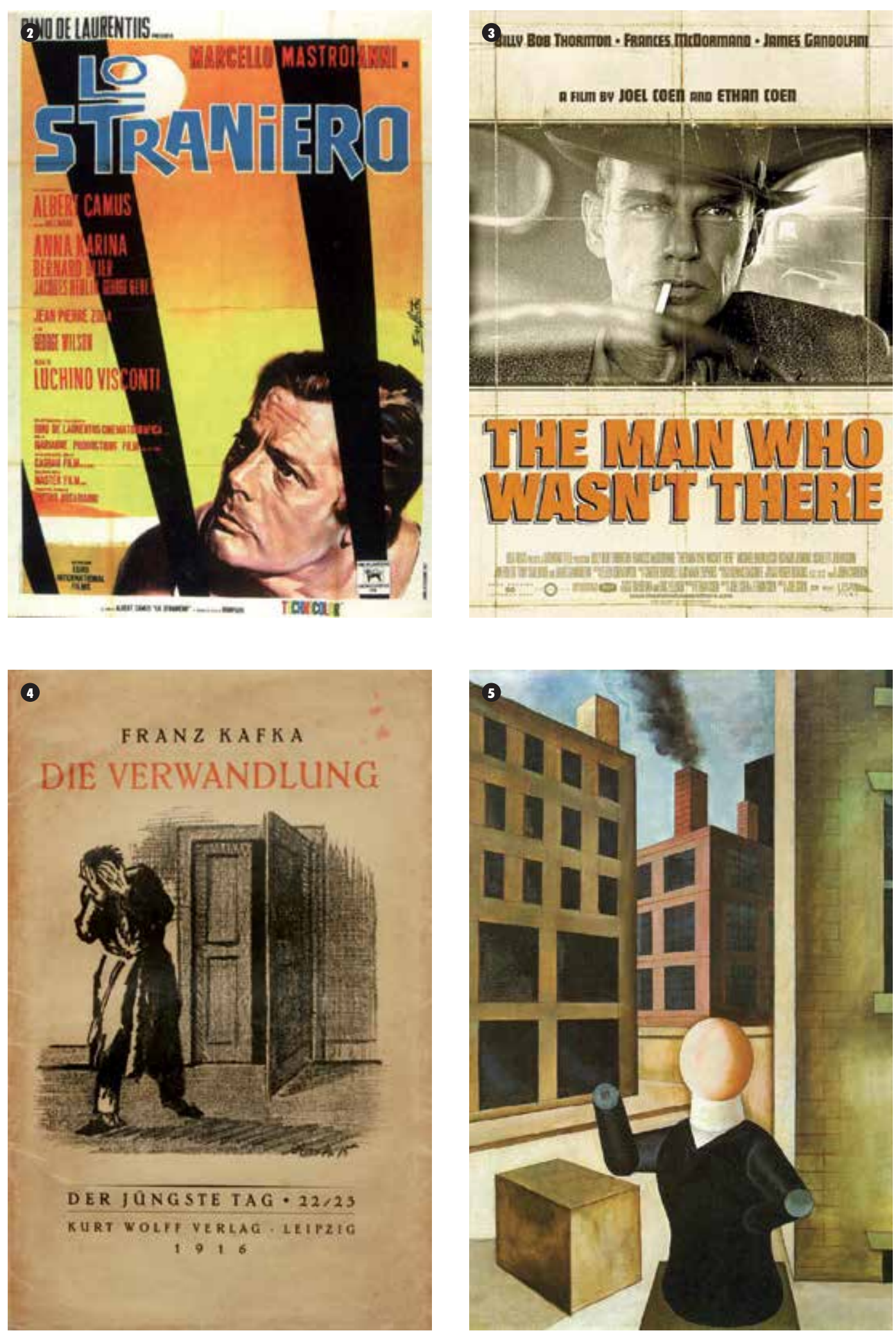
6. THE CITY de Georges Grosz (1916) (Fuente: http://bartleby.blogsome.com/wp-admin/ images/grosz4.JPG).
7. KilLING an ARAB, portada del primer sencillo editado por The Cure (1979) (Fuente: http://danielcunado.files. wordpress.com/2012/10/the-cure-killing-an-arab.jpg). Esta polémica canción -muchas veces ha sido considerada por error racista-, la definió Robert Smith, su compositor, como un intento poético de condensar sus impresiones sobre la obra de Camus, El extranjero (Cure News n ${ }^{\circ} 11$, octubre de 1991).
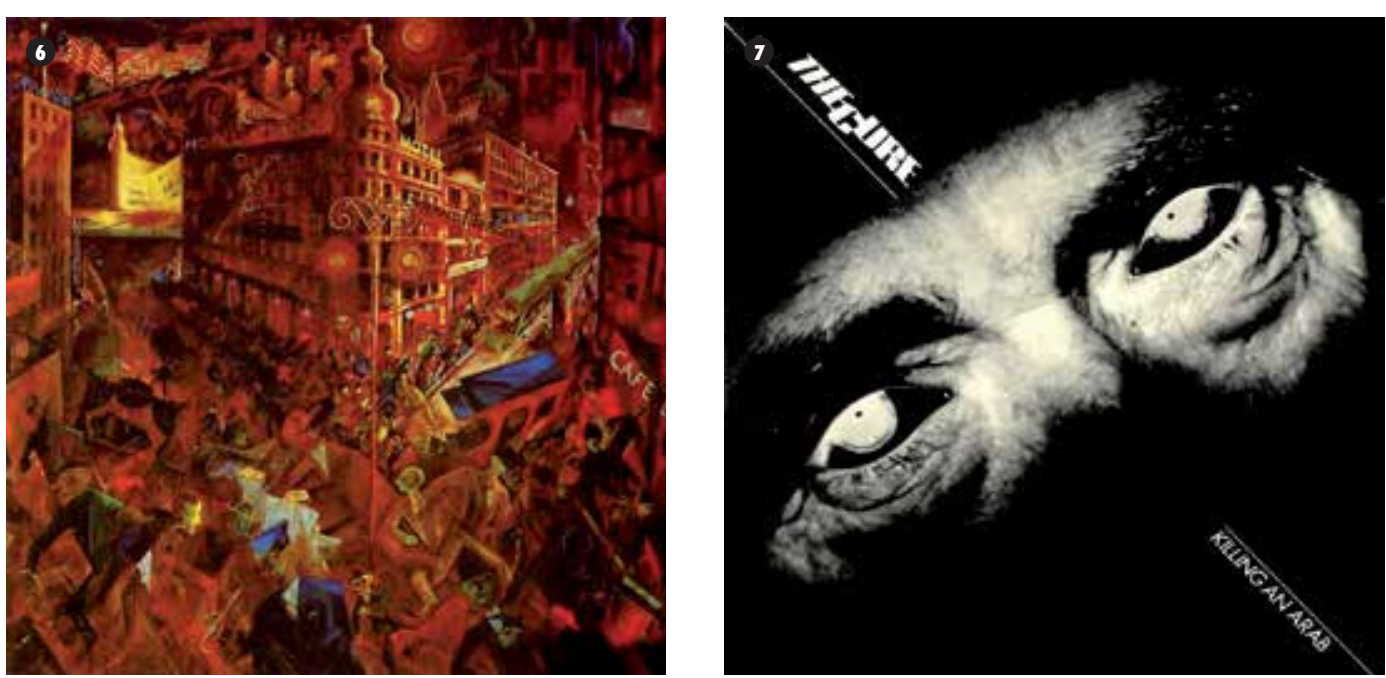

\section{SOBRE EL CONCEPTO DE NO-LUGAR}

Estos personajes, sintetizados en M. Meursault, impregnados del grado cero ${ }^{[1]}$, se pueden comparar con los no-lugares, como lugares sin alma donde su mayor característica es la presencia abrumadora de la ausencia, que nos pesa y a la vez nos hace sentir libres al flotar en la nada, en la ausencia de todo.

Este des-inter-es de querer sumergirse en la vida o en el interior de sí mismo, esta vivencia desde el exterior puede ser la que lo lleve a ser un extraño, un extranjero incluso para sí mismo.

Infiriendo este concepto de extranjero, se podría identificar con los no-lugares, como lugares sin alma, sin interior, lugares fuera de sí, sin-lugares.

Así, los no-lugares se caracterizan ante todo por una ruptura con el ser humano quien se siente inquilino y no propietario, fuera-de: un mundo que no es el suyo, de lo establecido, y aunque si bien la ex-sistencia es en sí misma la posibilidad de estar fuera de donde se está, como afirma Morales (1999); esta escisión

(1] Se hace referencia al grado cero propuesto por Barthes como «una escritura indicativa o amodal» (2003), que la define como neutra aspirando a una lengua básica con una ausencia total de estilo. tan pronunciada provoca una fragmentación el entorno tanto físico, histórico, así como un quiebre con el pasado y el presente, enfocando solamente el futuro, generando una suerte de "giro-copernicano» o descentramiento donde el sujeto pasa a ser objeto y al revés; donde el centro de la arquitectura y el lugar ya no es el ser humano sino el consumo, la economía, todos los movimientos y los flujos asociados a ella, pasando el ser de estar-en, a un estarhacia, de un reposo a un movimiento que corre cada vez más veloz.

Y es que pareciera que todo va más rápido, que cada vez se «necesita» mayor velocidad en las comunicaciones, en los trabajos... es curioso que teniendo todo mecanizado, sin embargo, se tiene «menos» tiempo que nunca.

¿No tenemos tiempo para nada o nada para el tiempo?, parafraseando a Julián Marías.

Este aumento de velocidad ha hecho que seamos víctimas del tiempo en nuestro tiempo, donde la espacialidad se reduce a la temporalidad; y si el lugar es la coexistencia de espacio y tiempo, como define Leibniz, o del tiempo en el espacio, como puntualiza Hegel, se podría hablar de una des-lugarización con este desfase del tiempo en relación al espacio, donde la experiencia no se puede cimentar y todo se con el contexto, una implosión y explosión en encapsula para poder exiliarse, sumergirse en los flujos.

«Exilio, ese lugar donde no solo no está en su casa sino que está fuera de sí mismo, en el afuera mismo, una región absolutamente privada de intimidad, en la que los seres parecen ausentes, en la que todo lo que cree aprehender se sustrae». Maurice Blanchot (1992)

No-lugar como exilio del lugar y de nosotros mismos. Así, se puede definir el no-lugar, que implica además de exilio físico: espiritual, pues es un afuera de todo. No-lugar que produce náuseas por su aplastante vacío, su nada. Ese «retorno a lo insignificante» del que habla Blanchot es la esencia del no-lugar.

No-lugares que pueden llegar a producir un vértigo, "vértigo del vacío» como posibilidad de saltar a ese vacío, como el miedo a quedarnos desterrados, a quedarnos exiliados: errantes sin relación con nosotros mismos, suspendidos en el no-lugar, nadando en una ausencia.

Ausencia como característica esencial del nolugar. Ausencia de permanencia, del reposo que reside en los lugares, ausencia de recuerdos y, por tanto, ausencia de evocación hacia ellos, de poderlos narrar, rozando la no-existencia.

Así, un no-lugar sería también un lugar desprovisto de los seres que lo han habitado, donde ya no se vive, donde la ausencia inunda la presencia de todo, la presencia de los seres humanos a los que estábamos acostumbrados a ver morar allí, a ser-ahí-en el lugar.

\section{NO-LUGAR Y LUGAR}

Mientras los lugares ${ }^{[2]}$ están ligados al ser, a un «espacio humanamente habitable dotado de significado» (Espósito, 2012), a presencia, a permanencia, a una cuestión de interior, los no-lugares son de carácter temporal, vinculados con el movimiento, el cambio, ya que tienen un tramo de no residencia, de pura exterioridad, hasta que otra vez se habitan. 
Asemejándose este ciclo a una banda de Moebiuss ${ }^{[3]}$, pues más que dos caras de una misma moneda, lugar y no-lugar forman parte de una «superficie unifaz que se pliega y deviene exterior y al plegarse de nuevo se convierte en exterior, sucediéndose o seduciéndose». (Gallardo, 2011).

Estando los lugares relacionados con el equilibrio, el genius loci, con el pasado pero anclándose al presente y abiertos hacia el futuro, siendo capaces de captar al ser humano y que el ser humano los capte.

Sin embargo, los no-lugares están relacionados con la incertidumbre, el no-saber. Espacios de «flujos» por y para el movimiento, la prisa, el sin-ser... cobijos de no-tiempo, envoltorios sin presente ni pasado, dirigiéndose solo hacia un futuro incierto.

...«Y siempre ha existido la instancia del no-lugar, pero quizá es ahora cuando su materialización se ha hecho más evidente que nunca.

Si bien la definición que plantea Augé como un «espacio que no puede definirse ni como espacio de identidad, ni como relacional, ni como histórico» (2004) describe perfectamente los no-lugares, sin embargo, la hipótesis que se sostiene desde aquí es que, y al contrario de lo expresado por Augé, los no-lugares al igual que los lugares han existido desde que existe el ser humano.

Augé plantea que los no-lugares son producto de la sobremodernidad, de la superabundancia $y$, si bien con esta superabundancia donde «todo policosmismo es un acosmismo» (Anders, 2007). Emerge con fuerza el no-lugar, este existe desde que existe el lugar, pues al igual que la racionalidad se sirve de la irracionalidad para constituirse como tal, como subraya Benjamin, también los lugares se sirven de los no-lugares para constituirse como tales. No-lugar como límite del lugar y viceversa.

Hay no-lugares que duran «un momento» porque en seguida los adaptamos o se adaptan transformándose en lugares, pero otros siempre permanecerán como no-lugares, como búsqueda continua, incesante.

No-lugares que por su no-identidad implican que se puedan evocar otros lugares dándole cabida a la imaginación y ofreciendo por tanto una posibilidad de estar fuera de donde se está, posibilidad de volverse como el giro de Orfeo hacia Eurídice.

«La mirada de Orfeo es así, el momento extremo de la libertad, momento en que se vuelve libre de sí mismo y, acontecimiento más importante, que libera a la obra de su preocupación, libera lo sagrado contenido en la obra, da lo sagrado a sí mismo, a la libertad de su esencia, a su esencia que es libertad (la inspiración es por esto el don por excelencia). Todo se juega entonces en la decisión de la mirada. En esa decisión se aproxima al origen por la fuerza de la mirada que libera la esencia de la noche, que aleja la preocupación, interrumpe lo incesante descubriéndolo: momento del deseo, de la despreocupación y de la autoridad». Blanchot, EL ESPACIO LITERARIO (1992).

A partir de este volverse Orfeo hacia Eurídice ${ }^{[4]}$ se puede comprender la metáfora del pliegue ${ }^{[5]}$ del lugar al no-lugar afín de ir más allá, hacia el no-lugar y desde ahí, buscar el lugar.
8. Orpheus and Eurydice de G. Kratzenstein-Stub (1806). Obra que se encuentra en el NY Carlsberg Glyptotek, Copenhague (Fuente: http://tejiendoelmundo.files. wordpress.com/2009/07/orfeo_euridice.jpg).

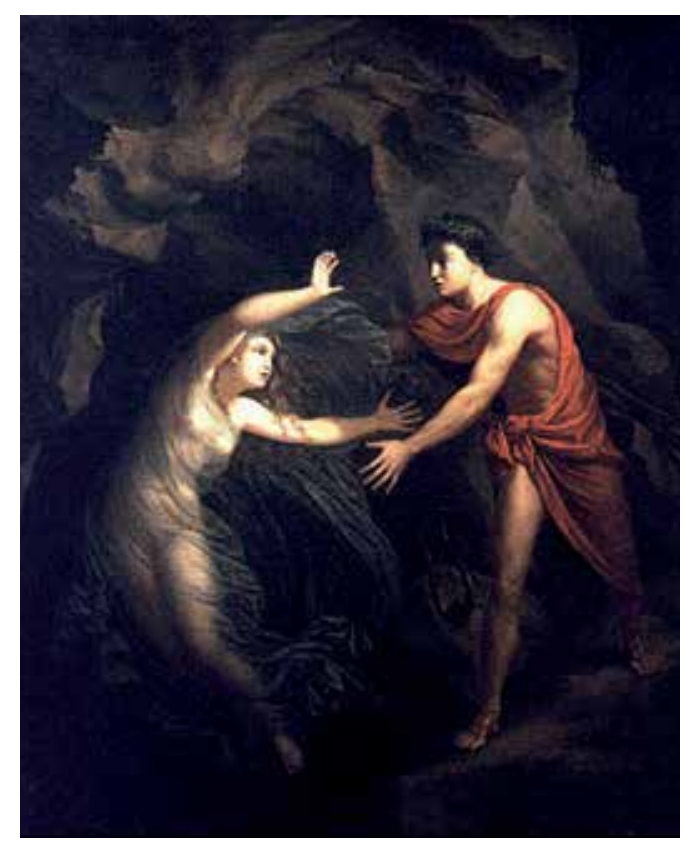

Giro de Orfeo hacia Eurídice vinculado con el movimiento de mirar hacia atrás en busca del anhelo de lo prohibido, de lo que ya no puede ser ni será porque al contemplarlo se transforma en nada; llevando asociados por tanto, la búsqueda de aspiración-a, de llegar-a... como característica inherente del ser humano.

No-lugares que solo remiten a un flujo sin presente ni pasado, pero que se vuelven a plegar para ofrecer un lugar, siendo este nuevo pliegue una consecuencia de nuestra «domesticación del no-lugar» o capacidad de «crear lazos» dotándolo de sentido.

Así, el lugar se «pliega» o se quiebra, saliéndose de su quicio, de su ciclo «natural» para doblarse hacia un sector de las sombras. Y tras este quiebre se vuelve a producir otro giro del

[2] Nótese la diferencia, a grandes rasgos, entre Espacio y Lugar, como indica Montaner (2011): Espacio: tiene una condición ideal, teórica, genérica e indefinida

Lugar: posee un carácter concreto, empírico, existencial, articulado, definido hasta los detalles.

[3] Se recuerda que la banda o cinta de Moebius fue codescubierta en forma independiente por los matemáticos alemanes August Ferdiand Möbius y Johann Benedict Listing en 1858. Si bien esta cinta, este ciclo solo tiene una cara, al girarse, cambia de dirección, cambia de «sentido» adquiriendo una nueva significación.

[4] Además de las múltiples pinturas, algunas de las representaciones más famosas del mito de Orfeo son: la ópera de Claudio Monteverdi, L'ORfeO, Favola IN músıca (1607) una de las primeras de la historia; Gluck también con Orfeo y Eurídice; el poema de Quevedo, Un Orfeo burlesco; también Los sonetos a OrfeO, de Rilke; y la TrILogía de Cocteau basada también en este mito.

[5] Noción de pliegue que también hace referencia a la obra homónima de Deleuze. 
no-lugar al lugar, que como el faro, sigue de nuevo inmerso en el movimiento circular que nos alumbra de nuevo con su luz.

Sin embargo, «no es la luz lo que importa en verdad, son los 12 segundos de oscuridad» ${ }^{[6]}$, es solo a partir del no-lugar, de sumergirnos en la oscuridad cuando podremos apreciar la luz, la presencia de los lugares.

\section{NO-LUGAR Y ARQUITECTURA}

El no-lugar puede ser transformado por la arquitectura entendiendo a esta como «arte de dar lugars $\rangle^{[7]}$, dotándolo de puntos significativos e identidad, anudándolo a su contexto y al ser humano; pero también puede quedarse siendo no-lugar como «espacio del anonimato», como define Augé, sin ninguna referencia, aunque siempre con esta «latencia» como posibilidad de llegar a ser lugar.

Hay que tener presente que la arquitectura es tan solo una especie de «semilla»: proyecto arquitectónico como lugar en potencia. Según indica Fernández Alba, es posible proyectar desde la arquitectura, pero «el lugar solo se puede construir desde el "fluir" de la vida» (1989); pues el que finalmente otorga la característica de lugar es el ser humano: principal lugar.

¿Se podría plantear que la arquitectura forma no-lugares por su «imposición» al lugar? Si bien es cierto que la arquitectura supone una transformación, no se debe olvidar que es un arte, el arte de dar lugar donde es posible dialogar con el contexto; pero también es cierto que la edificación, cuando está totalmente desligada del ser humano y su entorno, también puede ser formadora de no-lugares, que no están pensados para ese contexto en concreto y surgen con la mala planificación o con la repetición de un modelo «ad infinitum».

Se podría hacer la distinción de dos tipos de nolugares: los planificados, como los aeropuertos, centros comerciales (no-lugares para el visitante) y los no-planificados, como sectores marginales, de abandono, de la periferia como «forma desnuda del no-lugar» que plantea Augé, o intersticios no-definidos. Fuerte contraste entre sitios $^{[8]}$ totalmente planificados para los flujos con otros irresolutos, aunque en ambos casos son no-recordados, ya que no ofrecen un lugar para el ser humano.

Pero sucede que a veces la proporción de lugar apenas es perceptible con lo que el no-lugar emerge aparentemente en su totalidad y a ese determinado sitio lo llamamos no-lugar y, en otras ocasiones, el lugar se hace presente opacando casi por completo al no-lugar tomando la definición de lugar. Pero la tesis es que siempre uno está comprendido en el otro sucediéndose, y lo que antes era un lugar ahora puede ser un no-lugar y a la inversa.

Con lo que se habla de arquitectura cuando sea arte y aunque esté pensada para los flujos se pueda ver en ella ese «algo más» que sin duda hace referencia a emerger la posibilidad del lugar por sobre el no-lugar.

\section{PROPUESTA DE NECESIDAD DEL NO-LUGAR}

No se debe olvidar que «Yo soy yo y mi circunstancia», como afirma Ortega y Gasset en Meditaciones del QuiJote ${ }^{[9]}$, donde esta circumstantia se puede interpretar como el lugar que se busca continuamente en la vida y que, sin embargo, ya poseemos pues somos nosotros mismos. "Circum-stantita» que nos acompaña albergando el movimiento alrededor-de "circum», y «stantia», la quietud. Lugar y Nolugar uno inmerso en el otro.

Con lo que se subraya la necesidad del nolugar, al igual que se necesita el lugar.

No-lugares donde momentáneamente reside la «colectividad sin festejo y la soledad sin aislamiento», como indica Augé (2002), pudiéndose encontrar un potente calmante para la intimidad consigo mismo (que se disipa al salir), pues ofrecen una posibilidad de estar fuera de donde se está; y aunque es necesario salir del lugar donde se vive para no tener apegos, como devela S. Agustín ${ }^{[10]}$, los no-lugares trascienden al apego queriendo ser una liberación del lugar que arroja a los seres humanos a sentirse extranjeros, como fuera de todo incluso de sí mismos; una especie de exilio-fugaz donde, por un momento, se puede abrazar la totalidad, pero que de repente se transforma en una pesada nada, en una ausencia del «todo» que parecía haberse tocado.

«Desde dentro es el único posicionamiento para la acción. Desde fuera es la situación narrativa imprescindible para la reflexión». Seguí (2010).

No-lugar como fórmula para eliminar el dolor, como devela Sennett (1997) a partir de la teoría de Wittgenstein, pues si el sufrimiento físico no cuenta con ningún objeto del mundo exterior, entonces los grandes volúmenes de Boullée marcan el punto en que la sociedad secular pierde el contacto con el dolor. Ya que con esta arquitectura revolucionaria creían que se podía llenar un volumen vacío, libre de obstáculos y restos del pasado, con significados humanos; resolviendo las necesidades de una nueva sociedad: un espacio sin obstrucciones. Con

[6] Canción 12 segundos DE OSCURIDAD, procedente del álbum homónimo de Jorge Drexler, 2006. Recordemos que curiosamente los faros se miden por la oscuridad cuando siempre esperamos su luz.

[7] Norberg-Schulz, en L'ART DU LIEU, afirma que «el arte del lugar, o la arquitectura, a la que concierne por principio todo lo vivido, es calificada con el justo título de "madre de las artes"» (1997).

[8] Nótese la diferencia entre sitio y lugar, pudiéndose «convertir un «sitio» indeterminado en un «lugar» irrepetible y singular» como indica Montaner (2011).

[9] «Yo soy yo y mi circunstancia, y si no la salvo a ella no me salvo yo. (...) Es decir, buscar el sentido de lo que nos rodea». Ortega y Gasset (1968).

[10] «Incluso si este vagar no es físico, debe perderse el apego al lugar en que se vive». San Agustín, LA CIUDAD DE DiOS (Sennett, 1997). 
lo que era posible eliminar el dolor eliminando el lugar, creencia que también se practica en nuestros días.

Necesidad del no-lugar donde se sumergen las personas que quieren formar lugares. No-lugar como salida del lugar, como «salir a tomar el aire» para poder aspirar profundamente y regresar de nuevo al lugar.

Al escribir, al pintar, al narrar, el artista se introduce en un no-lugar, donde toma conciencia de sí mismo, de que su esencia proviene del no-ser, con lo que es a partir de la ausencia con la que se puede llegar a obtener la presencia del lugar.

Al narrar, como explica de Certeau, se finge ser su otro, por lo que se practica el no-lugar. Narrar como anudar las artes del decir con las del hacer, narrar para conectar interior-exterior.

Narración como existencia, para darnos cuenta que estamos aquí, ique estamos vivos! Narrar desde un no-lugar para lugarizar nuestra existencia, materializarla dotándola de sentido y cobijo donde ser. Con lo que se pone de manifiesto la importancia del no-lugar para apreciar el lugar, cómo el no-lugar también es necesario, aunque implique sumergirnos en la ausencia.

Ausencia donde solo es posible imaginar.. como afirma Proust en LE TEMPS RETROUVÉ, «no se puede imaginar sino lo que está ausente». Quizás sea una de las causas del «enganche» a estos no-lugares, pues hacen volar la imaginación.

Otro punto que justifica la necesidad de revalorizar los no-lugares es que constituyen un «refugio para la diversidad» como indica Clément al describir el TeRCER PAISAJE, pues en ellos todo cabe, convirtiéndose en una alternativa del lugar. No-lugares elevados, por tanto, a la categoría de posibilidad.

En estos lugares de la nada: todo adquiere sentido, "en la nada todo encuentra su lugar», afirma Givone (2001), «todo es en la nada: todo lo lleno está en el vacío, todo ente reposa sobre el no-ente y encuentra asilo en él como en un lugar».

Por ello esta nota de seducción tan viva en los no-lugares, que si bien no son lugares que nos acogen, sí tienen la habilidad de seducirnos en su aproximación a tocar lo universal, para rozar un instante la prohibida eternidad, la nada, el no ser.

Nada como el verdadero objeto de la nostalgia, por ello nuestro re-encuentro con ella en los nolugares, como contenedores de nostalgia ${ }^{[1]}$ : del deseo sin objeto, de la pasión de la ausencia.

De ahí la importancia del no-lugar como quiebre, como lugar extranjero para re-valorizar, hacer emerger al lugar y posibilitar que su resonancia llegue hasta nosotros.

\section{REFERENCIAS BIBLIOGRÁFICAS}

Anders, G. Hombre sin mundo. Escritos sobre arte y literatura. Valencia: Editorial Pre-textos, 2007; 81 $87,17$.

Augé, M. Los no lugares. Espacios del anonimato. Una antropología de la sobremodernidad. Barcelona: Gedisa S.A., 2004; 83.

Augé, M. El viajero subterráneo. Barcelona: Gedisa S.A., 2002.

Barthes, R. El grado cero de la escritura. Argentina: Siglo XXI Editores, 2003; 78

Blanchot, M. El espacio literario, España: Ediciones Paidós Ibérica S.A., 1992; 70, 165

Camus, A. El extranjero. Barcelona: Editorial Planeta, 1999; 110.

Certeau, M. de. La invención de lo cotidiano. 1 Artes de hacer. México, D.F.: Universidad Iberoamericana A.C., 1996.

Clément, G. Manifiesto del tercer paisaje. Barcelona Editorial Gustavo Gili, 2007
Deleuze, G. El pliegue. Leibniz y el Barroco. Barcelona: Paidós Básica, 1989.

Espósito Galarce, F.M. «El "afecto" en la arquitectura: la relación entre arquitecto, lugar y habitante en la experiencia contextual del proyecto». Arquitecturarevista 2012; 8(1):9.

Fernández Alba, A. Sobre la naturaleza del espacio que construye la arquitectura (Geometría del recuerdo y proyecto del lugar). Madrid: Real Academia de Bellas Artes de San Fernando, 1989.

Gallardo Frías, L. «Vínculo interior-exterior. Una reflexión sobre la arquitectura el lugar y el nolugar». Revista R180 (UDP) 2011 ; 27:5.

Givone, S. Historia de la nada. Buenos Aires: Adriana Hidalgo Editorial S.A., 2001; 213

Kafka, F. La metamorfosis. Madrid: Huerga y Fierro Editores, 2006

Kundera, M. La ignorancia. Barcelona: Tusquets Editores, 2000; 12

Montaner, J.M. La modernidad superada. Ensayos sobre arquitectura contemporánea. Barcelona: Gustavo Gili, 2011 ; 33, 38.

Morales, J.R. Arquitectónica. Sobre la idea y el sentido de la arquitectura. Madrid: Editorial Biblioteca Nueva, 1999; 162

Norberg-Schulz, C. L'Art du lieu. Architecture et paysage, permanence et mutations. Trad. de I'italien par Anne Guglielmetti. París: Groupe Moniteur, 1997; 194

Ortega y Gasset, J. Meditaciones del Quijote. Bilbao: Ediciones Aguilar, 1968; 50.

Perec, G. Tentativa de agotar un lugar parisino Rosario: Beatriz Viterbo Editora, 1992

Seguí de la Riva, J. «Dibujar proyectar XVI: sin arquitectura». Cuadernos del Instituto Juan de Herrera de la Escuela de Arquitectura de Madrid 2009

Seguí de la Riva, J. Ser dibujo. Madrid: Escuela Técnica Superior de Arquitectura de Madrid, 2010; 23

Sennett, R. Carne y piedra. El cuerpo y la ciudad en la civilización occidental. Madrid: Alianza, 1997 140,400 .

[1] En LA IGNORANCIA, Kundera explica que «nostos» en griego significa regreso y «algos» sufrimiento, con lo que la nostalgia es el sufrimiento por el deseo incumplido de regresar, lo que implica la pérdida de un territorio. Tiene relación con la palabra saudade en portugués o añoranza en español, que proviene del verbo «añoran», y a su vez del catalán enyorar, derivado del verbo latino ignorare (ignorar, no saber de algo); con lo que «la nostalgia se nos revela como el dolor de la ignorancia: estás lejos, y no sé qué es de ti» (2000). 